International Journal of Engineering \& Technology, $9(1)(2020) 9-11$
International Journal of Engineering \& Technology
WPC
Website: www.sciencepubco.com/index.php/IJET
Research paper

\title{
Applying al-zughair transform on nuclear physics
}

\author{
Emad A. Kuffi ${ }^{1}$ *, Ali Hassan Mohammed ${ }^{2}$, Ameer Qassim Majde ${ }^{3}$, Elaf Sabah Abbas ${ }^{4}$ \\ ${ }^{1}$ Dr. Assistant professor Al-Qadisia University, Baghdad, Iraq \\ ${ }^{2}$ Msc. Professor, Department of Mathematics, Faculty of Education for girls, University of Kufa, Baghdad, Iraq \\ ${ }^{3}$ Master Student, Department of Mathematics, University of Kufa, Baghdad, Iraq \\ ${ }^{4}$ Msc. Assistant lecturer, Communication Engineering department, Al-Mansour University Collage, Baghdad, Iraq \\ *Corresponding author E-mail: elaf.abbas@muc.edu.iq
}

\begin{abstract}
Al-Zughair transform is a novel transformation that is proposed in (2017), and due to its novelty it has not been applied to engineering fields, however Al-Zughair transform is capable to solve differential equations, for that reason it can be applied into engineering applications that include differential equations. In nuclear physics the radioactive decay of the atoms is well study subject, where there are many methods that are used to deal with it, however Al-Zughair transform has never been used before in that field, in this paper the differential equation of radioactive decay has been solved using Al-Zughair transform.
\end{abstract}

Keywords: Al-Zughair Transform; Differential Equations; Nuclear Physics; Radioactive Decay; Atom; A-Decay; $\Gamma$-Decay; B-Decay.

\section{Introduction}

Since the beginning of the modern physics in (1895), atoms were a very interesting subject to the scientists, that's lead to the development of the nuclear physics. In nature most atoms are stable and don't emit energy, however there are some atoms that need to emit energy in order to become stable. The radioactive decay of the uranium and thorium containing natural elements is represents the base for the nuclear physics. The radioactive decay could happen naturally or induced by artificial methods. There are many types of nuclear decays that depends on the type of emitted radiation such as $\alpha$-decay, $\gamma$-decay, $\beta$-decay and other types as shows in figure 1. [ 1 - 3] [8].

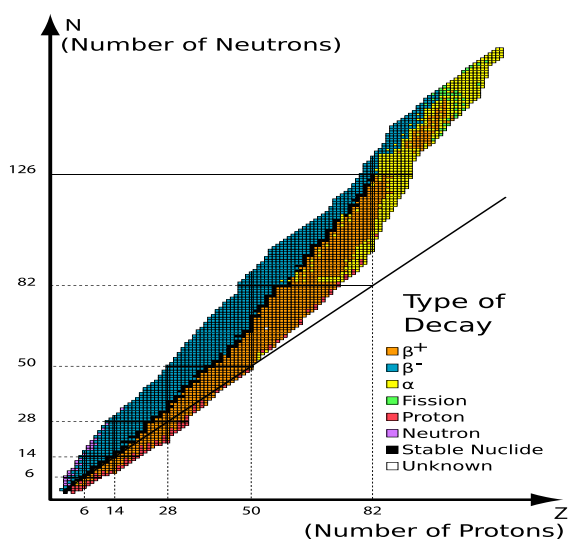

Fig. 1: Nuclear Decay of Isotopes.

There are many methods that solved the radioactive decay of the atoms [1 - 4] [7] [8], however Al-Zughair transform never been used before in such application. Al-Zughair transform is a novel transformation that emerged at 2017, it is a an efficient transformation that can be used in solving the ordinary differential equations, and for that reason it can be used in many engineering fields [5], [6].

\section{Basic concepts}

In order to make the calculation clearer, it is necessary to mention some definitions, functions, properties and theorems

\subsection{Definition [6]}

Copyright $\odot$ Emad A. Kuffi et al. This is an open access article distributed under the Creative Commons Attribution License, which permits unrestricted use, distribution, and reproduction in any medium, provided the original work is properly cited. 
Al-Zughair transformation for the function $f(x)$, is defined by the following integral: $Z[f(x)]=\int_{1}^{e} \frac{(\ln x)^{p}}{x} f(x) d x=F(p)$. Such that this integral is a convergent and $\mathrm{p}$ is a constant that is greater than $(-1)$.

\subsection{Propriety, [6]}

Al-Zughair transformation is characterized by the linear property, which is: $\mathrm{Z}[\mathrm{Af}(\mathrm{x}) \mp \mathrm{Bg}(\mathrm{x})]=\mathrm{AZ}[\mathrm{f}(\mathrm{x})] \mp \mathrm{BZ}[\mathrm{g}(\mathrm{x})]$. Where A and $\mathrm{B}$ are constants, the functions $\mathrm{f}(\mathrm{x})$ and $\mathrm{g}(\mathrm{x})$ are defined when $\mathrm{x} \in[1, \mathrm{e}]$.

\begin{tabular}{lll}
\hline Function on $\mathrm{f}(\mathrm{x})$ & $\mathrm{F}(\mathrm{p})=\int_{1}^{\mathrm{e}} \frac{(\ln \mathrm{x})^{\mathrm{p}}}{\mathrm{x}} \mathrm{f}(\mathrm{x}) \mathrm{dx}=\mathrm{Z}[\mathrm{f}(\mathrm{x})]$ & Region of convergence \\
\hline $\mathrm{k}, \mathrm{k} \equiv \mathrm{constant}$ & $\frac{\mathrm{k}}{\mathrm{p}+1}$ & $\mathrm{p}>-1$ \\
$(\ln \mathrm{x})^{\mathrm{n}}, \mathrm{n} \in \mathrm{R}$ & $\frac{1}{\mathrm{p}+(\mathrm{n}+1)}$ & $\mathrm{p}>-(\mathrm{n}+1)$ \\
$\ln ((\ln \mathrm{x}))^{\mathrm{n}}, \mathrm{n} \in \mathrm{Z}^{+}$ & $\frac{(-1)^{\mathrm{n}} \mathrm{n}}{(\mathrm{p}+1)^{\mathrm{n}+1}}$ & $\mathrm{p}>-1$ \\
$\sin (\mathrm{a} \ln (\ln \mathrm{x}))$ & $\frac{-\mathrm{a}}{(\mathrm{p}+1)^{2}+\mathrm{a}^{2}}$ & $\mathrm{p}>-1$, a is a constant \\
$\cos (\mathrm{a} \ln (\ln \mathrm{x}))$ & $\frac{\mathrm{p}+1}{(\mathrm{p}+1)^{2}+\mathrm{a}^{2}}$ & $\mathrm{p}>-1$, a is a constant \\
$\sinh (\mathrm{a} \ln (\ln \mathrm{x}))$ & $\frac{-\mathrm{a}}{(\mathrm{p}+1)^{2}-\mathrm{a}^{2}}$ & $|\mathrm{p}+1|>\mathrm{a}, \mathrm{a}$ is a constant \\
$\cosh (\mathrm{a} \ln (\ln \mathrm{x}))$ & $\frac{\mathrm{p}+1}{(\mathrm{p}+1)^{2}-\mathrm{a}^{2}}$ & $|\mathrm{p}+1|>\mathrm{a}, \mathrm{a}$ is a constant \\
\hline
\end{tabular}

\subsection{Al-Zughair transform for some fundamental functions, [6]}

\subsection{Theorem, [6]}

If $Z[f(x)]=F(p)$ and a is a constant, then $Z\left[(\ln x)^{a} f(x)\right]=F(p+a)$.

\subsection{Definition, [6]}

Let $f(x)$ be a function, $x \in[1, e]$ and $Z[f(x)]=F(p), f(x)$ is said to be an inverse of Al-Zughair transformation and written as: $Z^{-1}[F(p)]=f(x)$. Where $Z^{-1}$ returns the transformation to the original function.

Note: $Z^{-1}$ has the linear propriety as it is for Al-Zughair transformation.

\subsection{Theorem, [6]}

If $Z^{-1}[F(p)]=f(x)$, then $Z^{-1}[F(p+a)]=(\ln x)^{a} f(x)$, where a is a constant.

\subsection{Theorem, [6]}

If the function $y(\ln x)$ is defined for,$x \in[1, e]$ and its derivatives $y^{\prime}(\ln x), y^{\prime \prime}(\ln x), \ldots, y^{(n)}(\ln x)$ are exist, then: $Z\left[(\ln x)^{n} y^{(n)}(\ln x)\right]=y^{(n-1)}(1)+(-1)^{2 n+1}(p+n) y^{(n-2)}(1)+(-1)^{2 n+2}(p+n)(p+(n-1)) y^{(n-3)}(1)+\cdots+(-1)^{3 n-1}(p+$ $n)(p+(n-1)) \ldots(p+2) y(1)+(-1)^{3 n}(p+n) ! F(p)$.

Note: for $n=1, Z\left[\ln x \cdot y^{\prime}(\ln x)\right]=y(1)-(p+1) Z[y(\ln x)]$.

\section{Radioactive decay in nuclear, [4] [8]}

In a period of time, the number of disintegrated nuclei in a radioactive sample decreases exponentially, which is serve as a way to identify a nuclide.

In any given sample the rate of radioactive decay is proportional to the number of each type of radioactive nuclei.

The rate of disintegration of radioactive nuclei $=$ decay constant $\times$ number

of radioactive nuclei present. This statement can be translated into the first order linear differential equation: $\frac{d N}{d t}=-\lambda N(3.1)$.

Where $N=N(t)$ represents the number of undecayed atoms remaining in a sample of a radioactive isotope at time $t$ and $\lambda$ is the decay constant.

\section{Solving the radioactive decay using al-zughair transform}

It is possible to write the equation (3.1) as:

$\frac{d N}{d t}+\lambda N=0$

Let $N=N(\ln t),-\infty<\ln (t)<\infty$ and $1 \leq t \leq e$.

Then equation (4.1) becomes:

$\frac{d N(\ln t)}{d t}+\lambda N(\ln t)=0$ 
By multiplying equation (4.2) by $\ln t$ :

$\ln t \cdot N^{\prime}(\ln t)+\lambda \ln t \cdot N(\ln t)=0$

By taking Al-Zughair transform to equation (4.3):

$Z\left[\ln t \cdot \frac{d N(\ln t)}{d t}\right]+\lambda Z[\ln t \cdot N(\ln t)]=0$.

By using theorems (2.4) and (2.7), the equation will become:

$N(1)-(p+1) Z[N(\ln t)]+\lambda N^{*}(P+1)=0$.

$-(p+1) Z[N(\ln t)]=-\lambda N^{*}(P+1)-N(1)$.

So $Z[N(\ln t)]=\frac{\lambda N^{*}(P+1)+N(1)}{p+1}$.

Then: $Z[N(\ln t)]=\frac{\lambda N^{*}(P+1)}{p+1}+\frac{N(1)}{p+1}$.

The solution of equation (4.3) is:

$N(\ln t)=\lambda Z^{-1}\left[\frac{N^{*}(P+1)}{p+1}\right]+N(1) Z^{-1}\left[\frac{1}{p+1}\right]$

By using table (2.3):

$N(\ln t)=\lambda Z^{-1}\left[\frac{N^{*}(P+1)}{p+1}\right]+N(1)(1), N(\ln t)=\lambda Z^{-1}\left[\frac{N^{*}(P+1)}{p+1}\right]+N(1)$.

Or, the general solution is:

$N(p)=\lambda \frac{N^{*}(P+1)}{p+1}+\frac{N(1)}{p+1}$. Where $Z[N(\ln t)]=F(p)$, and $p>-1$

\section{Conclusions}

Al-Zughair transformation is capable of solving functions and differential equations, either by using its table (table 2.3) or by using its definition and theorems.

The previous calculation proved the ability of Al-Zughair transformation of providing a new and simplified general method to solve the radioactive decay ordinary differential equation: $\frac{d N}{d t}=-\lambda N$ through time period $1 \leq t \leq e$, where it is assumed that: $\forall t \in[1, e], N(t)=$ $N(\ln t), N(\ln 1)=N_{0}$ at $t=1$ as intial condition, and $N(\ln e)=N(1)$ at $t=e$ as end condition . Based on theorems $(2.4)$, (2.7) and table (2.3) of Al-Zughair transformation.

\section{References}

[1] Jean-Louis Basdevant, James Rich, Michel Spiro, "Fundamentals in Nuclear Physics: From Nuclear Structure to Cosmology", Springer, (2005).

[2] Kenneth S. Krane, "Introductory Nuclear Physics", John Wiley and sons, (1988).

[3] Khairi Mohammad Said Abdullah, "Fundamentals in Nuclear Physics", University of Duhok, (2014)

[4] L.S. Sawant, “Applications of Laplace transform in Engineering Fieldes”, International Research Journal of Engineering and Technology, Volume (5), Issue (5), (2018).

[5] Mahammed AH, Abdullah NG, “AL-Zughair Transform of Differentiation and Integration”, International Journal of Pure and Applied Mathematics, Volume (119), NO. (16), (2018).

[6] Mahammed AH, Sadiq BA, Hassan AM, “Al-Zughair Transform”, LAP Lambert Academic Publishing, (2017).

[7] Sujaul Chowdhury, Ponkog Kumar Das, "Numerical Solutions of Initial Value Problems Using Mathematica", Morgan \& Claypool, 2018. https://doi.org/10.1088/978-1-6817-4976-1.

[8] Walter D. Loveland, David J. Morrissey, Glenn T. Seaborg, "Modern Nuclear Chemistry", second edition, Wiley, (2017). https://doi.org/10.1002/9781119348450. 